\title{
Estudo macroscópico e dinamométrico comparativo de implantes (ímãs recobertos) e de suas técnicas de fixação em órbitas de coelhas
}

\author{
Comparative macroscopic and dynamometric study of implants(covered magnets)and \\ techniques of their fixation in orbits of female rabbits
}

Elcio Roque Kleinpaul ${ }^{1}$

Harley Edison Amaral Bicas ${ }^{2}$

\section{RESUMO}

Objetivos: Avaliação clínica dos sinais da reação inflamatória de fixação de implante orbitário (ímã recoberto por ouro) e avaliação macroscópica de sua resistência aos fluidos orgânicos. Métodos: Estudo experimental em 54 coelhas adultas, divididas em três grupos de 18, com 3 subgrupos de 6 de acordo com o material usado para fixação, avaliação com uma, três e seis semanas de pós-operatório. Fixação, no rebordo inferior da órbita, de implante (ímã e ouro) por meio de cola ou parafuso ou fio inabsorvível (Mersilene 5.0 ${ }^{\circledR}$ ). As órbitas contralaterais (sem implante) compuseram o grupo-controle. Medidas da resistência à tração tangencial do implante fixado. Resultados: Sinais clínicos de reação inflamatória à fixação orbitária do implante foram observados com cianoacrilato, parafuso, ou sutura inabsorvível (Mersilene 5.0 ${ }^{\circledR}$ ), até a sexta semana de pós-operatório, sendo mais intensa no grupo F (fixação com fio). A força de tração de 80 gf, independentemente do tipo de fixação, não produziu arrancamentos em 94,5\% dos implantes na primeira semana, $100 \%$ na terceira semana e em $94,5 \%$ dos casos na sexta semana. Conclusão: Sinais clínicos de reação inflamatória do implante e sua fixação foram observados com cianoacrilato ou parafuso ou sutura inabsorvível (Mersilene $5.0^{\circledR}$ ) até a sexta semana pós-operatória, sendo mais intensa no grupo $\mathrm{F}$ (fio). A resistência do implante aos fluídos orgânicos mostrou falha em 9,3\% (implante com dano).

Descritores: Magnetismo/uso terapêutico; Ouro/efeitos adversos; Nistagmo patológico/ cirurgia; Coelhos; Feminino

\section{INTRODUÇÃO}

Universidade de São Paulo - Faculdade de Medicina de Ribeirão Preto - Departamento de Oftalmologia, Otorrinolaringologia e Cirurgia da Cabeça e Pescoço Av. Bandeirantes, 3900 - Ribeirão Preto (SP) CEP 14049-900

${ }^{1}$ Pós-graduando da Faculdade de Medicina de Ribeirão Preto da Universidade de São Paulo - USP.

${ }^{2}$ Professor Titular do Departamento de Oftalmologia, Otorrinolaringologia, Cabeça e Pescoço da Faculdade de Medicina de Ribeirão Preto da Universidade de São Paulo - USP.

Endereço para correspondência: Elcio Roque Kleinpaul - Av. Presidente Wilson, 174/53 - Santos (SP) CEP 01065-201

E-mail: elcioroq@ig.com.br

Recebido para publicação em 25.02.2003

Versão modificada recebida em 17.07.2003

Aprovação em 18.02.2004

\begin{abstract}
Apesar de avanços na área de motricidade ocular, há uma lacuna importante no que diz respeito à geração de forças binoculares combinadas, para restauração de perdas de ação muscular ou para o bloqueio de vários tipos de nistagmo, nos quais a correção cirúrgica não atinge os objetivos propostos.

Estudos têm sido realizados para se tentar substituir as forças musculares, utilizando-se métodos de contato material direto ou indireto. $\mathrm{O}$ contato material direto (músculos ou fios elásticos presos à esclera) oferece algumas desvantagens: os vínculos entre o material e o olho sofrem interferências mecânicas de tecidos vivos, neoformações cicatriciais.

Uma alternativa é o possível aproveitamento de campos magnéticos ( sem contato material direto entre o elemento gerador de força e sua aplicação sobre o olho). A principal desvantagem é a distância entre os elemen-
\end{abstract}


tos, ou seja, com pequenos aumentos nas distâncias entre os elementos do campo magnético, há uma diminuição muito grande da força transmitida ${ }^{(1)}$.

\section{Nistagmo}

Termo utilizado para descrever movimentos oculares oscilatórios, rítmicos e repetitivos.

Classifica-se o nistagmo de acordo com a manifestação clínica. O pendular mostra velocidade aproximadamente igual em ambos os sentidos e o sacádico caracteriza-se por apresentar duas fases com velocidades distintas, isto é, com o movimento em um sentido reconhecidamente mais rápido que o no sentido inverso. O movimento lento é devido à ação do músculo hiperfuncionante e o rápido é o corretivo ${ }^{(2)}$.

\subsection{Condutas terapêuticas nos nistagmos}

A terapêutica para o nistagmo tem-se mostrado limitada. $\mathrm{O}$ tratamento óptico mais difundido é o uso de prismas, que têm duas finalidades: corrigir o mau posicionamento da cabeça, resultante de uma posição de bloqueio, distinta da posição primária (bases dos prismas colocadas para o mesmo lado) e estimulação da convergência (bases colocadas lateralmente). Outra possibilidade é a substituição dos óculos pelas lentes de contato ${ }^{(2-3)}$.

O tratamento cirúrgico do nistagmo objetiva a melhoria da acuidade visual e eliminação do torcicolo. Os casos de nistagmos mais favoráveis são aqueles nos quais há posição de bloqueio total ou parcial ${ }^{(3)}$.

\subsection{Introdução de forças pelo uso de campos magnéticos}

O uso de forças de campo magnético para a correção de defeitos dinâmicos do sistema oculomotor sejam eles por falta de movimentos (paralisias neuromusculares, miopatias, agenesias ou desinserções musculares, etc.) ou para estabilizar os inadequados (nistagmos, lentas modificações posicionais após cirurgias, etc.), tem sido estudado, mostrando uma série de vantagens ${ }^{(4)}$. Forças magnéticas agem sem contato material direto entre o olho e a fonte e a condição de inocuidade aos tecidos biológicos.

\subsection{Elementos geradores de forças (ímãs)}

Apesar de uma disponibilidade grande de ímãs no mercado, são os compostos de Neodímio-Ferro-Boro (Ne-Fe-B) 27 e 30, uma liga, os que, presentemente, oferecem as maiores concentrações de fluxo magnético gerado por volume de material (possibilitando as melhores miniaturizações), condição muito necessária quando são pretendidos artefatos de tamanho reduzido, que viabilizem a construção de um circuito magnético adequado aos olhos.

Para a fixação do ímã na parede orbitária lateral, o ímã deve ser recoberto com uma película protetora (silicone ou ouro) para isolá-lo de tecidos e fluidos orgânicos, já que os ímãs mais adequados para a geração de força (ímã de $\mathrm{Ne}-\mathrm{Fe}-\mathrm{B}$ ) possuem, em sua composição, elementos que podem causar toxicidade.

Os boratos são utilizados em sabonetes, detergentes, fertilizantes, preservação da madeira, fabricação de fungicidas, e na preparação de tintas, pois retardam a propagação do fogo. A ingestão de ácido bórico ou absorção após a aplicação local podem levar a náuseas, vômitos, diarréia, anemia, convulsões e erupções cutâneas caracterizadas por eritema intenso, descamação e esfoliação e alopecia $^{(5)}$.

\subsection{Ouro como película protetora do ímã}

O ouro é muito utilizado na odontologia, especialmente na sua forma pura. É o mais nobre de todos os materiais empregados, raramente sofrendo corrosão. Na cavidade oral, ele é inativo quimicamente e não é afetado pelo ar, calor e umidade, nem pela maioria dos solventes. Seus possíveis efeitos nocivos sobre a polpa têm sido discutidos e, quando condensado adequadamente, produz resposta inflamatória pulpar mínima em uma estrutura dentária sadia ${ }^{(6)}$.

Este trabalho experimental visou contribuir para a concretização de aplicações práticas do uso do campo magnético em Oftalmologia, estudando-se aspectos da implantação do ímã à órbita.

\section{OBJETIVOS}

1. Avaliação macroscópica das órbitas durante a retirada do material per-implante, para exame histológico;

2. Verificação da resistência do implante aos fluidos orgânicos;

3. Teste da resistência tangencial do implante, por meio de um dinamômetro, durante abertura por planos.

\section{MÉTODOS}

\section{Materiais}

1) Ímãs de terra rara (neodímio, ferro e boro) recobertos com níquel, medindo $5 \mathrm{~mm}$ de diâmetro por 2,5 $\mathrm{mm}$ de altura, foram envolvidos por duas chapas de ouro maciças, uma de 10 micrômetros, envolvendo a parte anterior do ímã, e outra medindo 35 micrômetros, desde a base do ímã até o ápice, encontrando, então, a chapa de 10 micrômetros da face anterior. $\mathrm{O}$ implante (complexo formado pelo ímã e as duas chapas em ouro e a alça de fio monofilamentar inabsorvível para a dinamometria) mediu 13,0 mm horizontalmente e 3,0 mm verticalmente, sendo elaborado artesanalmente em um serviço privado e sempre pela mesma pessoa (Figura 1);

2) Coelhas Nova Zelândia de peso variando de 1,8 a $2,2 \mathrm{~kg}$, de 3 a 5 meses de vida, em número de 54, fornecidas pelo biotério da Faculdade de Medicina de Ribeirão Preto, da USP.

3) Fios de polipropileno 5.0, com agulha redonda de 1,5 cm;

4) Fios monofilamentares 5.0, com agulha cortante de $1,5 \mathrm{~cm}$;

5) Cola do tipo cianoacrilato, em forma de gel - Superbon$\operatorname{der}^{\circledR}$ (Loctite).

6) Parafusos de platina, de $5 \mathrm{~mm}$ de comprimento por 0,9 mm de diâmetro, auto-rosqueantes. 


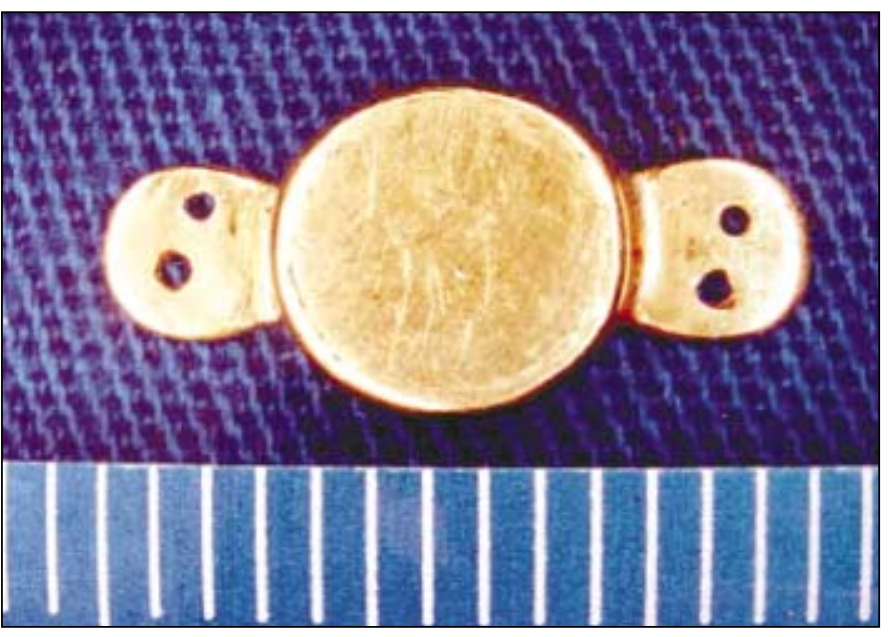

Figura 1 - Modelo utilizado, sem a alça, e sua medida horizontal

\section{MÉTODOS}

\section{Fixação do implante}

Após o envolvimento do ímã pelo ouro e colocação da alça de monofilamento inabsorvível, fixou-se esse implante na borda orbitária inferior das coelhas, por meio de fio de polipropileno 5.0 no periósteo ou cola do tipo cianoacrilato, em forma de gel, ou parafuso de platina auto-rosqueante.

\section{Animais}

As coelhas foram divididas em lotes (num total de 18), contendo 3 coelhas cada lote, e em tipos (1, 3, 6 semanas da implantação).

\section{Sorteio}

Sorteio da ordem dos tipos e dos grupos de pesquisa para cada lote (1-18). O grupo controle, para cada lote, foi constituído da órbita contralateral de cada coelha. Estas foram numeradas de 1 a 54 , ou seja, o lote número 1 , contendo três coelhas, contou com as coelhas 1, 2, 3, e assim por diante, respeitandose a ordem de chegada. Os animais foram retirados da mesma gaiola no biotério, levados no dia do implante e colocados em gaiolas, com três coelhas (correspondendo a um lote), da Cirurgia Experimental da FMRP-USP, para permanecerem juntos até a data da retirada do implante.

Para a classificação, as coelhas foram divididas em 3 grupos de pesquisa de 18 animais, C, P e F (cola, parafuso e fio, respectivamente). Cada um desses três grupos foi dividido em subgrupos com 6 coelhas, dependendo do tipo de fixação do implante e seu tempo de permanência, ou seja, C-1 para cola e uma semana, C-3 para cola e três semanas e C-6 para cola e seis semanas; $\mathrm{P}-1$ para parafuso e uma semana, $\mathrm{P}-3$ para parafuso e três semanas e P-6 para parafuso e seis semanas; F-1 para fio e uma semana, F-3 para fio e três semanas e F-6 para fio e seis semanas. As órbitas foram divididas em: tratadas com implante (ímã recoberto pelo ouro e a alça de monofilamento inabsorvível para dinamometria) e tratadas sem implante, ou seja, realizou-se a abertura por planos e não houve fixação do implante (controle).

\section{Procedimento cirúrgico}

Cada coelha foi pesada e, 10 minutos após administração da medicação pré-anestésica contendo Ketamina $2 \mathrm{ml}$ (IM) e Xilazina $1 \mathrm{ml}$ (IM), obteve-se acesso venoso e administraram-se $10 \mathrm{mg} / \mathrm{kg}$ de Tiopental (EV) para complementação anestésica; quando necessário, reforço de $10 \mathrm{mg} / \mathrm{kg}$ de Tiopental (EV).

Após tricotomia e antissepsia da pele, deu-se a abertura da borda orbitária inferior, com incisões de $2,5 \mathrm{~cm}$, dissecção por planos até o periósteo, que foi descolado para a fixação ou não (controle) do implante: no próprio periósteo, no caso do fio; ou no rebordo orbitário, no caso de cola ou parafuso.

Após a fixação do implante, ou não (órbita tratada sem implante), aproximou-se o subcutâneo com fio de polipropileno 5.0, agulha de $1,5 \mathrm{~cm}$, sutura contínua e a pele com fio monofilamentar inabsorvível 5.0, com agulha cortante de $1,5 \mathrm{~cm}$ (nylon 5.0), também com chuleio simples. A cada duas órbitas, trocou-se a lâmina do bisturi para minimizar o traumatismo e, a cada coelha, trocaram-se as luvas cirúrgicas.

\section{Retirada do implante}

No tempo da retirada do implante, as coelhas foram sacrificadas e foi realizada a abertura dos tecidos, por planos, até a localização do implante e do periósteo, na órbita contralateral (Figura 2).

\section{Avaliação macroscópica}

Avaliação macroscópica das seguintes condições: a) exame do implante, com dano (1) ou sem (0); b) secreção ausente (0) ou presente (1) (serosa, purulenta); c) fibrose de cada órbita (0) para ausência e (1) para presença. Partindo dos critérios acima, chegou-se à classificação da reação macroscópica em normal e anormal. Assim, adotou-se como anormalida-

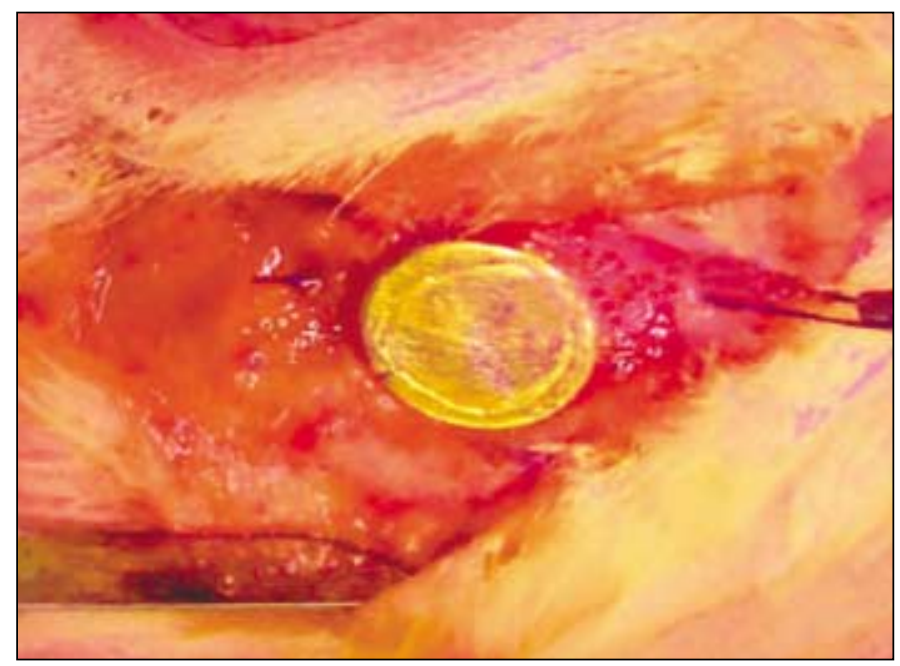

Figura 2 - Localização do implante e sua retirada após dinamometria 
de a presença de secreção purulenta e/ou a presença do implante com dano, e normalidade, a ausência do descrito acima.

\section{Dinamometria tangencial}

Após a avaliação clínica macroscópica, segurando o dinamômetro de Wagner, já calibrado, colocou-se o gancho do aparelho na alça do fio de monofilamento pré-existente no implante fixado na órbita e, então, foram realizadas as medidas de tração tangencial, com 20 gf, 40 gf, 60 gf, 80 gf (Figura 3).

\section{ANÁLISE ESTATÍSTICA}

Foram realizadas análises descritivas, quando nenhum teste estatístico de significância era adequado, ou a simples observação clínica era insuficiente para a tomada de decisões. Aplicou-se o programa Systat ${ }^{\circledR} 7.00$ aos estudos estatísticos. Para a comparação entre as órbitas tratadas com e sem implante, dentro de cada subgrupo, foi utilizado o teste não paramétrico de Wilcoxon, para dados pareados. Para o estudo entre os subgrupos de um mesmo grupo, nos seus respectivos períodos pós-operatórios, e para o estudo de diferentes subgrupos em um mesmo período, foi aplicado o teste não paramétrico de Mann-Whitney. Tais análises consideraram os seguintes aspectos:

- macroscopicamente: secreção serosa, purulenta e fibrose.

Em todos os testes, foram apresentados os valores de "p". Adotou-se o nível de significância de 5\% $(0,05)$.

\section{RESULTADOS}

Os aspectos clínicos da reação inflamatória ao implante e sua fixação nas órbitas das coelhas dos grupos C, P e F e seus subgrupos estão representados, respectivamente, nas tabelas 1 e 2 .

Observou-se reação macroscópica anormal em cinco órbitas tratadas; destas, uma do subgrupo C-3, uma do subgrupo

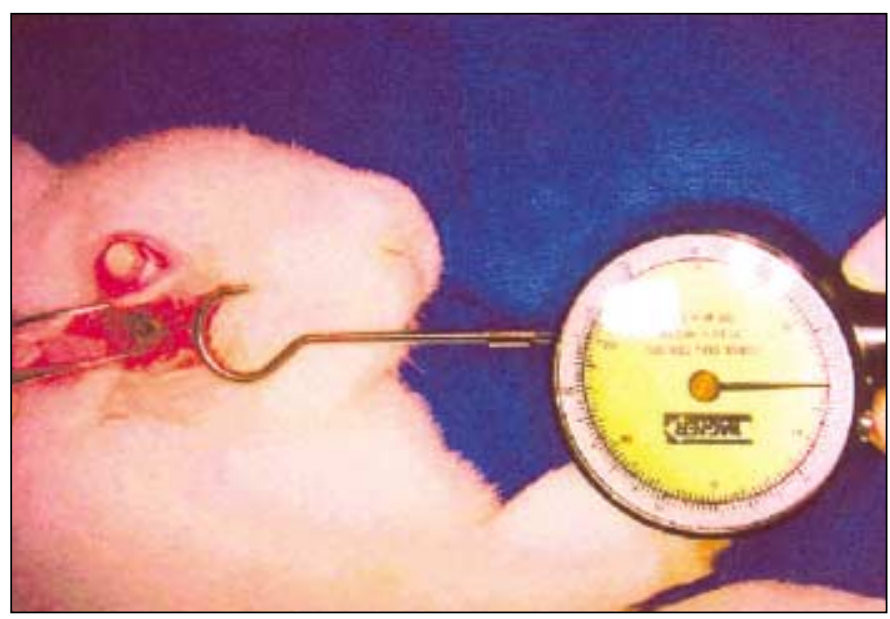

Figura 3 - Dinamometria tangencial (Dinamômetro de Wagner)
C-6, uma do subgrupo F-3 e duas do subgrupo F-6. A secreção purulenta esteve presente somente no subgrupo F-6.

As medidas das forças de tração tangencial, com o dinamômetro de Wagner, após a abertura por planos, estão quantificadas em gf, na tabela 3 .

\section{DISCUSS $\tilde{A} O$}

Para o presente estudo, optou-se pelo éster de cianoacrilato em forma de gel (Super Bonder ${ }^{\circledR}$, Loctite), devido ao seu baixo custo, facilidade de obtenção, melhor controle no momento de aplicá-lo no implante, rápida polimerização, solidificação instantânea em contato com a água e grupos básicos fracos encontrados em tecidos vivos, e também pelo fato de possuir efeito adesivo similar ao Histoacryl ${ }^{\circledR}$ (n-butil-2-cianoacrilato), comercializado pelo laboratório B. Braun, utilizado para uso médico ${ }^{(7)}$.

Estudo experimental comparativo sobre os efeitos dos

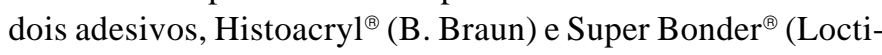
te), ambos derivados de cianoacrilato, no tratamento da perfuração corneana em cobaias, demonstrou resultados semelhantes nos aspectos clínico e histopatológico ${ }^{(7)}$.

$\mathrm{O}$ adesivo de cianoacrilato apresenta ação bacteriostática contra microorganismos Gram positivos, especialmente durante o processo de polimerização, apresentando bons resultados pela ausência do aparecimento de infecções após o seu uso ${ }^{(7-8)}$.

\begin{tabular}{|c|c|c|c|c|c|c|c|c|c|c|}
\hline & & & & & & & & & & \\
\hline clínicos & Subgrupos & $\mathrm{C}-1$ & $\mathrm{C}-3$ & C-6 & $\mathrm{P}-1$ & P-3 & P-6 & $\mathrm{F}-1$ & F-3 & F-6 \\
\hline $\begin{array}{l}\text { Secreção } \\
\text { serosa }\end{array}$ & $\begin{array}{l}\text { ausência } \\
\text { presença }\end{array}$ & $\begin{array}{l}2 \\
4\end{array}$ & 6 & 6 & $\begin{array}{l}2 \\
4\end{array}$ & 6 & 6 & $\begin{array}{l}2 \\
4\end{array}$ & 6 & $\begin{array}{l}4 \\
2\end{array}$ \\
\hline $\begin{array}{l}\text { Secreção } \\
\text { purulenta }\end{array}$ & $\begin{array}{l}\text { ausência } \\
\text { presença }\end{array}$ & 6 & 6 & 6 & $\begin{array}{l}6 \\
4\end{array}$ & 6 & 6 & 6 & $\begin{array}{l}6 \\
5\end{array}$ & 4 \\
\hline Fibrose & $\begin{array}{l}\text { ausência } \\
\text { presença }\end{array}$ & 6 & 6 & 6 & 2 & 6 & 6 & 6 & 1 & $\begin{array}{l}2 \\
6\end{array}$ \\
\hline $\begin{array}{l}\text { Dano } \\
\text { implante }\end{array}$ & $\begin{array}{l}\text { ausência } \\
\text { presença }\end{array}$ & 6 & $\begin{array}{l}5 \\
1\end{array}$ & $\begin{array}{l}5 \\
1\end{array}$ & 6 & 6 & 6 & 6 & $\begin{array}{l}5 \\
1\end{array}$ & $\begin{array}{l}4 \\
2\end{array}$ \\
\hline
\end{tabular}

\begin{tabular}{|c|c|c|c|c|c|c|c|c|c|c|}
\hline \multirow{3}{*}{$\begin{array}{l}\text { Achados } \\
\text { clínicos } \\
\text { Secreção } \\
\text { serosa }\end{array}$} & \multirow{3}{*}{$\begin{array}{c}\text { Grupo } \\
\text { Subgrupos } \\
\text { ausência } \\
\text { presença }\end{array}$} & \multirow{2}{*}{\multicolumn{3}{|c|}{$\frac{\text { C (Cola) }}{\text { C-1 C-3 C-6 }}$}} & \multicolumn{3}{|c|}{ P (Parafuso) } & \multicolumn{3}{|c|}{ F (Fio) } \\
\hline & & & & & $\overline{P-1}$ & $\mathbf{P}-3$ & P-6 & $\overline{F-1}$ & F-3 & F-6 \\
\hline & & 6 & 6 & 6 & $\begin{array}{l}5 \\
1\end{array}$ & 6 & 6 & $\begin{array}{l}5 \\
1\end{array}$ & 6 & 6 \\
\hline $\begin{array}{l}\text { Secreção } \\
\text { ourulenta }\end{array}$ & $\begin{array}{l}\text { ausência } \\
\text { presença }\end{array}$ & 6 & 6 & 6 & 6 & 6 & 6 & 6 & 6 & 6 \\
\hline Fibrose & $\begin{array}{l}\text { ausência } \\
\text { presença }\end{array}$ & 6 & 6 & 6 & $\begin{array}{l}4 \\
2\end{array}$ & 6 & 6 & 6 & 6 & 6 \\
\hline
\end{tabular}




\begin{tabular}{|c|c|c|c|c|c|c|c|c|c|c|}
\hline \multirow{3}{*}{$\begin{array}{l}\text { Dinamo- } \\
\text { metria } \\
\text { tangen- } \\
\text { cial em g } \\
20\end{array}$} & \multirow{3}{*}{$\begin{array}{c}\text { Grupo } \\
\text { Subgrupos } \\
\text { f } \\
\text { Resistiu } \\
\text { Não resistiu }\end{array}$} & \multicolumn{3}{|c|}{ C (Cola) } & \multicolumn{3}{|c|}{ P (Parafuso) } & \multicolumn{3}{|c|}{ F (Fio) } \\
\hline & & C-1 & $C-3$ & C-6 & P-1 & P-3 & P-6 & $\overline{F-1}$ & F-3 & F-6 \\
\hline & & 6 & 6 & $\begin{array}{l}5 \\
1\end{array}$ & 6 & 6 & 6 & 6 & 6 & 6 \\
\hline 40 & $\begin{array}{c}\text { Resistiu } \\
\text { Não resistiu }\end{array}$ & $\begin{array}{l}5 \\
1\end{array}$ & 6 & $\begin{array}{l}5 \\
1\end{array}$ & 6 & 6 & 6 & 6 & 6 & 6 \\
\hline 60 & $\begin{array}{c}\text { Resistiu } \\
\text { Não resistiu }\end{array}$ & $\begin{array}{l}5 \\
1\end{array}$ & 6 & $\begin{array}{l}5 \\
1\end{array}$ & 6 & 6 & 6 & 6 & 6 & 6 \\
\hline 80 & $\begin{array}{c}\text { Resistiu } \\
\text { Não resistiu }\end{array}$ & $\begin{array}{l}5 \\
1\end{array}$ & 6 & $\begin{array}{l}5 \\
1\end{array}$ & 6 & 6 & 6 & 6 & 6 & 6 \\
\hline
\end{tabular}

Apesar de os estudos sobre o adesivo biológico de fibrina ${ }^{(9)}$ terem demonstrado sua capacidade adesiva em cirurgias de músculos extra-oculares, o seu alto custo inibe o seu emprego em estudos experimentais. A dificuldade de sua obtenção pela técnica de crioprecipitação de fibrinogênio originário em banco de sangue também colabora para a sua não utilização. Além do exposto, o cianoacrilato forma uma proteção entre a esclera e a placa, pelo seu efeito na prevenção de aderências ${ }^{(10-11)}$, a qual poderá ser removida em caso de necessidade, não acontecendo o mesmo com o adesivo biológico de fibrina.

Quando possível, foram aplicados cálculos estatísticos e, quando não, descreveram-se as alterações. Comparando-se as órbitas com implante nos subgrupos (mesmo grupo), observou-se diferença estatisticamente significante, com $\mathrm{p}=0,02$, quanto à serosidade entre os tempos de uma e três semanas e 1s e 6 s, nos grupos C e P, e entre F-1 x F-3, no grupo F. Os achados são explicados pela presença de secreção serosa em quatro das seis órbitas, na primeira semana (grupos C, P e F), e a ausência em todas as órbitas, nas terceira (grupos C, P e F) e na sexta semana (grupos $\mathrm{C}$ e $\mathrm{P}$ ) pós-operatória. Não houve diferença estatística quanto à secreção purulenta. Já quanto à fibrose, somente no grupo P, entre P-1 x P-3 (fibrose ausente e presente em quatro e em todas as seis órbitas, respectivamente) e entre P-1 x P-6 (fibrose ausente e presente em quatro e em todas as seis órbitas, respectivamente), $\operatorname{com} \mathrm{p}=0,02$.

\section{Exame clínico na primeira semana do período pós-operatório}

Comparando-se as órbitas tratadas com implante e sem implante, observou-se diferença estatisticamente significante entre subgrupos C-1 $(p=0,05)$ e F-1 $(p=0,05)$, quanto à serosidade. A explicação dá-se pela ausência de secreção serosa nas órbitas tratadas sem implante, nos respectivos subgrupos citados. Não houve reação inflamatória purulenta nas órbitas tratadas com e sem implante. Observou-se diferença estatisticamente significante somente no subgrupo C-1 $(\mathrm{p}=0,01)$, quanto à fibrose, considerando-se as órbitas tratadas com e sem implante. Na comparação entre as órbitas trata- das com implante (C-1 e P-1; C-1 e F-1; P-1 e F-1), não se observou diferença estatisticamente significante quanto à secreção serosa nem quanto à purulenta. Já quanto à fibrose, observou-se diferença estatisticamente significante $(p=0,02)$ na comparação entre os subgrupos C-1 x P-1 e P-1 x F-1, nas órbitas tratadas com implante. No caso da comparação entre os subgrupos C-1 x P-1, justifica-se a presença da fibrose nas seis órbitas do subgrupo $\mathrm{C}-1$, e a ausência, em quatro das seis órbitas tratadas com implante, no subgrupo P-1. Comparandose as órbitas tratadas com implante nos subgrupos P-1 e F-1, verificou-se ausência da fibrose em quatro das seis e presença em todas as órbitas tratadas, respectivamente.

\section{Exame clínico na terceira semana do período pós-operatório}

Comparando-se as órbitas tratadas com implante com as tratadas sem implante, nos seus respectivos subgrupos C-3, P-3 e F-3, não se observou diferença estatisticamente significante quanto às secreções serosa (ausente em todas as órbitas), purulenta (ausente) e fibrose (presente em todas as órbitas desse período). $\mathrm{Na}$ comparação entre as órbitas tratadas com implante (C-3 e P-3; C-3 e F-3; P-3 e F-3), não se observou diferença estatisticamente significante quanto às secreções serosa, purulenta e fibrose. Das 18 órbitas tratadas com implante, em duas delas os implantes não estavam íntegros, no momento da retirada: um no subgrupo C-3 e outro no subgrupo F-3. Apesar da ruptura superior, não se observou secreção serosa e/ou purulenta.

\section{Exame clínico na sexta semana do período pós-operatório}

Comparando-se as órbitas tratadas com implante e tratadas sem implante, nos seus respectivos subgrupos C-6, P-6 e F-6, não se observou diferença estatisticamente significante quanto às secreções serosa, purulenta e fibrose (presente em todas as órbitas desse período). Na comparação entre as órbitas tratadas com implante (C-6 e P-6; C-6 e F-6; P-6 e F-6), não se observou, também, nível de significância quanto às secreções serosa, purulenta e fibrótica. Das 18 órbitas tratadas, em três delas os implantes não estavam íntegros, no momento da abertura para retirada dos tecidos, para o estudo histológico, nos subgrupos C-6 (cola), coelha 37, F-6 (fio), o animal 47 e, no subgrupo F-6, o animal 48. Nos dois últimos casos, observouse a presença de secreção purulenta.

\section{Resistência dos implantes aos fluidos orgânicos}

Observou-se clinicamente, na retirada do implante, ruptura superior, no encontro das chapa inferior e superior de ouro, em cinco $(9,3 \%)$ das 54 órbitas. Apesar disso, somente em duas órbitas a secreção purulenta fez-se presente (todas pertencentes ao subgrupo F-6 (fio, seis semanas). É possível que tal fenômeno (ruptura superior dos implantes) se deva a pequenos defeitos no momento de aproximar as duas chapas (a inferior com a superior), na parte superior do ímã, ainda que tenham sido elaboradas pela mesma pessoa (Figuras 4, 5 e 6). Estudos no Laboratório de Química da Universidade de São 


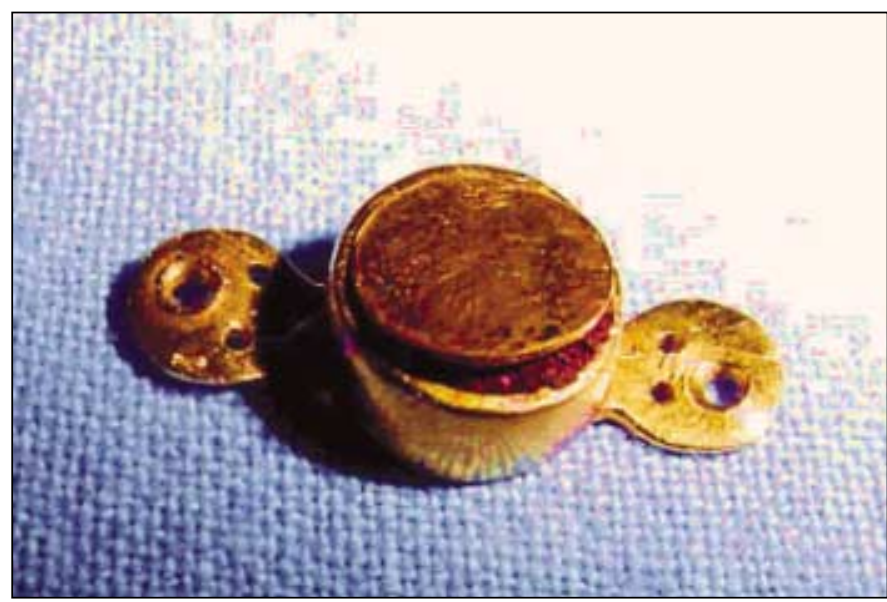

Figura 4 - Implante com ruptura parcial superior observada no momento da abertura por planos para dinamometria tangencial

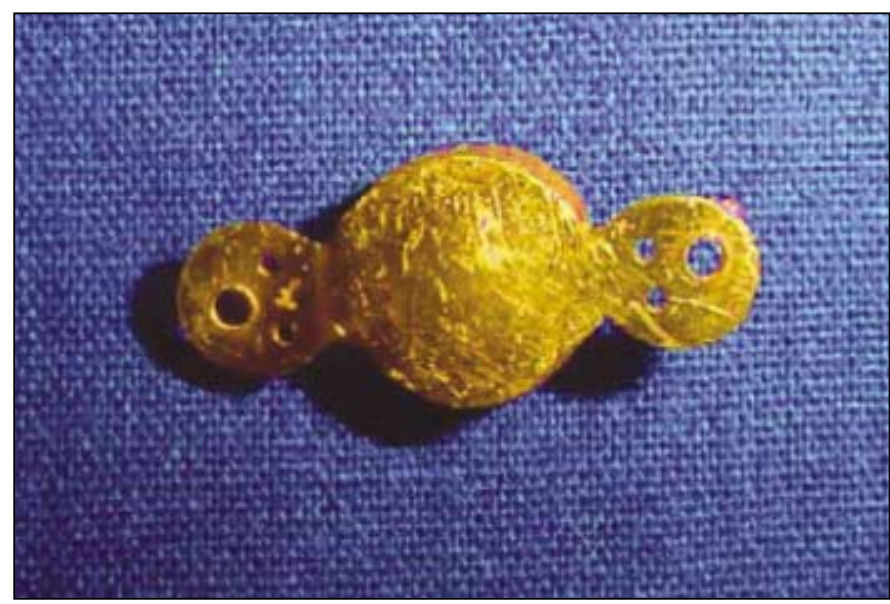

Figura 5 - Evidência da integridade na parte inferior do mesmo implante. Característica observada em todos os outros implantes danificados

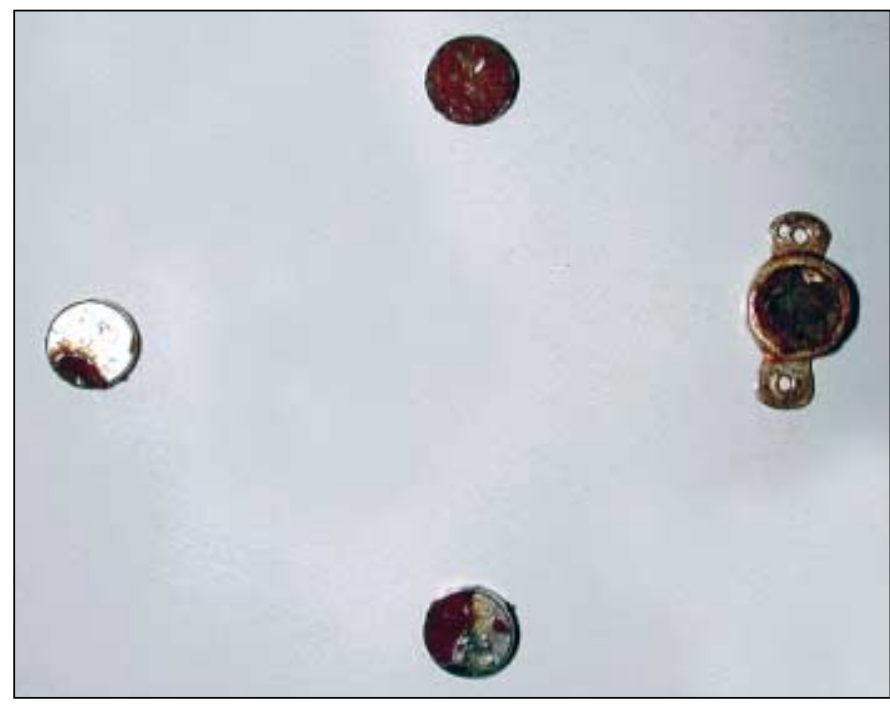

Figure 6 - Diversos ímãs danificados. Observação macroscópica durante a dinamometria
Paulo, sobre implantes danificados, demonstraram que a concentração de ouro foi de 94,5\%. (Figuras 4, 5 e 6 ).

\section{Medidas das forças de tração na fixação dos implantes}

A força com que os elementos magnéticos permanecem acoplados, garantindo rotações de 40 graus, deve resistir a trações de, pelo menos, 40 gf, pois, caso contrário, ocorre separação entre os elementos tracionante e tracionado ${ }^{(3)}$.

Adotou-se a medida máxima de 80 gf para execução das forças de tração tangencial à órbita, porque ela é suficiente para a comprovação da adesão da placa na esclera, como fator de segurança de $100 \%$ (força superior a $40 \mathrm{gf}$ ).

Na primeira semana, $83 \%$ dos implantes resistiram à tração tangencial de 40 gf, e de 80 gf no grupo C, cola. Nos grupos $\mathrm{P}$, parafuso e F, fio, também na primeira semana, $100 \%$ dos implantes resistiram à tração tangencial de 80 gf Na terceira semana, todos os grupos $(\mathrm{C}, \mathrm{P}$ e F) resistiram à tração tangencial de 80 gf Na sexta semana, $83 \%$ dos implantes resistiram à tração tangencial de 80 gf no grupo C. Nos grupos $\mathrm{P}$ e F, também na sexta semana, $100 \%$ dos implantes resistiram à tração tangencial de $80 \mathrm{gf}$ (Tabela 3).

A adesão do implante à órbita por meio da cicatriz tecidual foi muito boa na primeira semana pós-operatória, pois $94,5 \%$ das órbitas resistiram à tração tangencial de até $80 \mathrm{gf}$, independente do tipo (Tabela 3).

$\mathrm{Na}$ terceira semana, não foram observados descolamentos devido à tração tangencial de até $80 \mathrm{gf}$, independente do tipo (Tabela 3).

$\mathrm{Na}$ sexta semana, independente do tipo, verificou-se que todos os implantes resistiram à tração da força tangencial de 80 gf, exceto uma que estava solta por ocasião do ato cirúrgico, na sua retirada, não sendo aplicada força de tração tangencial. Os resultados mostram que, $98,1 \%$ dos implantes resistiram à força de tração de $40 \mathrm{gf}, 96,2 \%$ dos implantes resistiram à força de tração tangencial de $80 \mathrm{gf}$ e somente um (subgrupo cola e na sexta semana da pós-operatória) não estava aderido à superfície da órbita na ocasião da sua retirada (Tabela 3 ).

\section{CONCLUSÕES}

1) Sinais clínicos de reação inflamatória do implante e sua fixação foram observados com cianoacrilato ou parafuso ou sutura inabsorvível (Mersilene 5.0 ${ }^{\circledR}$ ) até a sexta semana pósoperatória, sendo mais intensa no grupo $\mathrm{F}$ (fio), já que das cinco órbitas tratadas com implante e que apresentaram danos, três pertenciam a este grupo, sendo que duas destas apresentaram secreção purulenta que creditamos à ruptura do implante na sua parte superior. É provável que o fator tempo seja responsável pela não observação de reação inflamatória purulenta em dois dos três implantes que estavam danificados visto que nestes a avaliação ocorreu na terceira semana pós-operatória.

2) O implante mostrou-se resistente aos fluidos orgânicos em $90,7 \%$ dos casos. Provavelmente houve falha no momento da sua montagem, o que se percebeu pelo dano no mesmo 
local em todos os casos, isto é, no encontro das duas chapas de ouro na parte superior.

3) A fixação do implante, na borda orbitária, avaliada pela força de tração tangencial aplicada, foi muito boa, independentemente do período pós-operatório. Na primeira semana, no grupo $\mathrm{C}$ (cola), $83 \%$ dos implantes resistiram à tração de 80 gf Nos grupos P (parafuso) e F (fio), também na primeira semana, $100 \%$ dos implantes resistiram à tração tangencial de $80 \mathrm{gf} \mathrm{Na}$ terceira semana, todos os grupos (C, P e F) resistiram à tração tangencial de $80 \mathrm{gf} \mathrm{Na}$ sexta semana, no grupo C (cola) $83 \%$ dos implantes resistiram à tração tangencial de 80 gf Nos grupos $\mathrm{P}$ (parafuso) e $\mathrm{F}$ (fio), também na sexta semana, $100 \%$ dos implantes resistiram à tração tangencial de $80 \mathrm{gf}$

A força de tração tangencial de $80 \mathrm{gf}$ apresentou melhores resultados nos grupos $\mathrm{P}$ (parafuso) e $\mathrm{F}$ (fio) e, apesar de no grupo $\mathrm{C}$ (cola) dois implantes não terem resistido à força tangencial especificada acima, esse tipo de fixação parece poder ser também utilizado com segurança.

\section{ABSTRACT}

Purpose: To evaluate the clinical signs of inflammatory reaction in the fixation of an orbitary implant (magnet, covered by gold), and to evaluate the macroscopic resistance to organic fluids of the used implants. Methods: An experimental study was performed in 54 adult female rabbits, divided into 3 groups of eighteen with 3 subgroups of 6 according to the material used for fixation; the implants were evaluated at weeks 1,3 and 6 after surgery. An implant (magnet, covered by gold) was fixed in the inferior edge of the orbit using glue, a screw or nonabsorbable suture (Mersilene 5.0 $0^{\circledast}$ ). The opposite orbits (without implants) represented the control group. Measurement of tangential traction of fixed implant displacement. Results: Clinical signs of inflammatory reaction due to orbitary fixation of the implant were observed, with glue (cyanoacrylate), screw or nonabsorbable suture (Mersilene 5.0 ${ }^{\circledR}$ ), until six weeks after surgery, the reaction being more severe in group F (suture). The implants showed resistance to organic fluids in $90.7 \%$ of the cases. The tangential traction force of $80 \mathrm{gf}$ showed better results in the groups where screw and unabsorbable suture were used, in the fixation group with glue two implants did not resist to that tangential force. Conclusions: Clinical signs of inflammatory reaction of the implant and its fixation were observed up to the sixth week after surgery, with cyanoacrylate, screw, or nonabsorbable suture (Mersilene $5,0^{\circledR}$ ), being more intense in the latter group. The traction force of $80 \mathrm{gf}$, regardless of the type of fixation, did not produce any displacement in $94.5 \%$ of the implants in the first week, $100 \%$ in the third week and in $94,5 \%$ of the cases in the sixth week. There was no resistance of the implants to organic fluids in 9.3\% (damaged implant).

Keywords: Magnetics/therapeutic use; Gold/adverse effects; Nystagmus pathologic/surgery; Rabbits; Female

\section{REFERÊNCIAS}

1. Bicas HEA. Gerações de rotações binoculares combinadas em casos de perdas de ação muscular: mecanismos para conjugações rotacionais. Arq Bras Oftalmol 1996;59:119-28.

2. Carvalho LEMR. Nistagmo. Arq Bras Oftalmol 1998;61:473-5.

3. Bicas HEA. Ajustamentos posicionais oculares e estabilizações do equilíbrio oculomotor sem impedir rotações. Arq Bras Oftalmol 1998;61:294-304.

4. Bicas HEA. Cirurgia dos nistagmos. In: XIV do Conselho Latino-Americano de Estrabismo. Anais. São Paulo; 2000. p.109-16

5. Louria DB. Intoxicação por oligoelementos. In: Cecil RL, Wyngaarden JS, Smith LH, Bennett JC, editors. Tratado de Medicina Interna. 19a ed. Rio de Janeiro: Guanabara Koogan; 1993. p.216-25.

6. Kenneth JA. Restaurações diretas em ouro e sua manipulação. In: Phillips. Materiais dentários. 10a . ed. Rio de Janeiro: Guanabara Koogan; 1998. p.241-7.

7. Wendler ME, Falzoni WL, Falzoni R. Adesivos teciduais no tratamento de perfuração corneana. Estudo comparativo em cobaias. Arq Bras Oftalmol 1983; 46:138-40.

8. Fenzl TC, Fenzl R, Harris L. Antimicrobial properties of alkyl-2-cyanoacrilate tissue adhesives in vitro. Am J Ophthalmol 1983;95:125-6.

9. Moreira ATR, Torres LF, Scarpi MJ, Moreira Jr. AM, Miranda SP, Matsumoto LH. Uso do adesivo biológico de fibrina para reinserção de músculos retos superiores em coelhos - Estudo clínico. Rev Bras Oftalmol 1998;57:501-12.

10. Dunlap EA, Dunn M, Rossomondo RBS. New uses for ocular adhesives. Arch Ophthalmol 1969;82:756-60.

11. Silva LH, Bicas HEA, Cruz AAV. Prevenção de aderências músculo-esclerais. Um estudo experimental. Arq Bras Oftalmol 1985;59:82-5.

\title{
ABO ELETRÔNICO
}

\author{
Novo site
}

\section{Acesso: http://www.abonet.com.br}

